\title{
Review on the Major Antimicrobial Resistance Bacterial Pathogen of Poultry
}

\author{
Bushura Regassa* and Meksud Mohammed \\ College of Veterinary Medicine and Animal Science, University of Gondar, Ethiopia \\ Submission: May 24, 2019; Published: June 19, 2019 \\ *Corresponding author: Bushura Regassa, College of Veterinary Medicine and Animal Science, University of Gondar, Ethiopia
}

\begin{abstract}
Antimicrobial resistance (AMR) is a global health threat, and antimicrobial usage and AMR in animal production is one of its contributing sources. Poultry flocks are often raised under intensive conditions using large amounts of antimicrobials to prevent and to treat disease, as well as for growth promotion. Antimicrobial resistant of poultry pathogens may result in treatment failure, leading to economic losses, but also be a source of resistant bacteria/genes (including zoonotic bacteria) that may represent a risk to human health. Here I reviewed data on AMR in poultry pathogens, including avian pathogenic Escherichia coli (APEC), Salmonella Pullorum/Gallinarum, Pasteurellamultocida, Clostridiumperfringens, Mycoplasma spp, Avibacteriumparagallinarum, Gallibacteriumanatis, Ornitobacteriumrhinotracheale (ORT) and Bordetella avium. A number of studies have demonstrated increases in resistance over time for S. Pullorum/Gallinarum, M. gallisepticum, and G. anatis. Among Enterobacteriaeae, APEC isolates displayed considerably higher levels of AMR compared with S. Pullorum/Gallinarum, with prevalence of resistance over $>80 \%$ for ampicillin, amoxicillin, tetracycline across studies. Among the Gram-negative, non-Enterobacteriaceae pathogens, ORT had the highest levels of phenotypic resistance with median levels of AMR against co-trimoxazole, enrofloxacin, gentamicin, amoxicillin, and ceftiofur all exceeding $50 \%$. In contrast, levels of resistance among P. multocida isolates were less than $20 \%$ for all antimicrobials. AMR poses considerable health hazards to the consumers unless prudent antimicrobial usage, adequate heat treatment, improvement of standards of hygiene and development and enforcement of suitable legislation, which safeguard consumers, are urgently instituted.
\end{abstract}

Keywords: Antimicrobial resistance; Antimicrobials; Bacterial pathogen

\section{Introduction}

Antibiotics (chemical substances produced by various microorganisms), synthetic chemicals, disinfectants, or drugs, collectively referred to as antimicrobial agents, have been used since the time of antiquity to treat patients with a variety of bacterial diseases [1]. Antimicrobial resistance (AMR) is a worldwide health concern [2]. Over recent years a considerable body of evidence highlighting the contribution of antimicrobial usage (AMU) and AMR from animals to the overall burden of AMR has emerged [3]. A contributing factor is the excessive use of antimicrobials in food animal production. The magnitude of usage is expected to increase considerably over coming years due to intensification of farming practices in much of the developing world [4]. Much of our knowledge and assumptions on the prevalence and evolution of AMR in animal production systems relate to organisms that more often than not are commensal in poultry such as Escherichia coli [5], Enterococcus spp., and Staphylococcus aureus [6] as well as foodborne zoonotic pathogens, such as non-typhoid Salmonella (NTS) [7] and Campylobacter spp. [8].
Poultry is one of the most widespread food industries worldwide, and chicken is the most commonly farmed species, with over 90 billion tons of chicken meat produced per year [9]. The main reasons are the relatively low production costs and the absence of cultural and religious restrictions for its consumption. A large diversity of antimicrobials is used to raise poultry in most countries [10], mostly through the oral route, with the aim to prevent and to treat disease, but also to enhance growth and productivity [11]. A large number of such antimicrobials are considered to be of critical and high importance for human medicine [12]. However, with some exceptions, relatively little is known on the prevalence and mechanisms of AMR in pathogenic bacteria in food animal production, including poultry.

\section{Antimicrobial Susceptibility Testing}

The goal of antimicrobial susceptibility testing is to predict the in vivo success or failure of antibiotic therapy. Tests are performed in vitro and measure the growth response of an isolated organism to a particular drug or drugs. The tests are performed under stan- 
dardized conditions so that the results are reproducible. The test results should be used to guide antibiotic choice.

\section{Broth dilution tests}

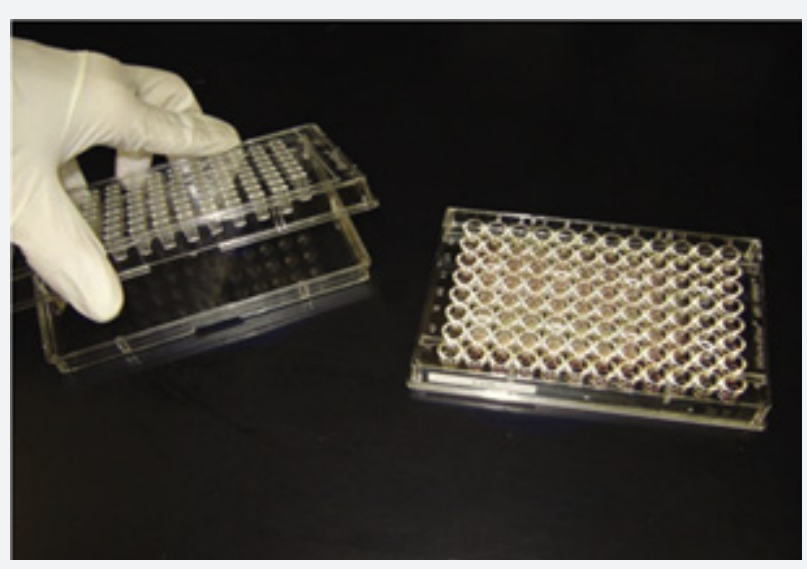

Figure 1: Broth microdilution susceptibility panel containing 98 reagent wells and a disposable tray inoculator.

One of the earliest antimicrobial susceptibility testing methods was the macrobroth or tube-dilution method [13]. This procedure involved preparing two-fold dilutions of antibiotics (eg, 1, 2, 4,8 , and $16 \mu \mathrm{g} / \mathrm{mL}$ ) in a liquid growth medium dispensed in test tubes [14]. The antibiotic-containing tubes were inoculated with a standardized bacterial suspension of $1-5 \times 105 \mathrm{CFU} / \mathrm{mL}$. Following overnight incubation at $35^{\circ} \mathrm{C}$, the tubes were examined for visible bacterial growth as evidenced by turbidity. The lowest concentration of antibiotic that prevented growth represented the minimal inhibitory concentration (MIC). The precision of this method was considered to be plus or minus 1 two-fold concentration, due in large part to the practice of manually preparing serial dilutions of the antibiotics [15]. The advantage of this technique was the generation of a quantitative result (ie, the MIC). The principal disadvantages of the macrodilution method were the tedious, manual task of preparing the antibiotic solutions for each test, the possibility of errors in preparation of the antibiotic solutions, and the relatively large amount of reagents and space required for each test.The miniaturization and mechanization of the test by use of small, disposable, plastic "microdilution" trays (Figure 1) has made broth dilution testing practical and popular. Standard trays contain 96 wells, each containing a volume of $0.1 \mathrm{~mL}$ that allows approximately 12 antibiotics to be tested in a range of 8 two-fold dilutions in a single tray. Microdilution panels are typically prepared using dispensing instruments that aliquot precise volumes of preweighed and diluted antibiotics in broth into the individual wells of trays from large volume vessels. Hundreds of identical trays can be prepared from a single master set of dilutions in a relatively brief period. Few clinical microbiology laboratories prepare their own panels; instead frozen or dried microdilution panels are purchased from one of several commercial suppliers. The cost of the preprepared panels range from approximately $\$ 10$ to $\$ 22$ each. Inoculation of panels with the standard $5 \times 105 \mathrm{CFU} / \mathrm{mL}$ is accomplished using a disposable device that transfers 0.01 to $0.05 \mathrm{~mL}$ of standardized bacterial suspension into each well of the microdilution tray or by use of a mechanized dispenser. Following incubation, MICs are determined using a manual or automated viewing device for inspection of each of the panel wells for growth [14].

\section{Disk diffusion test}

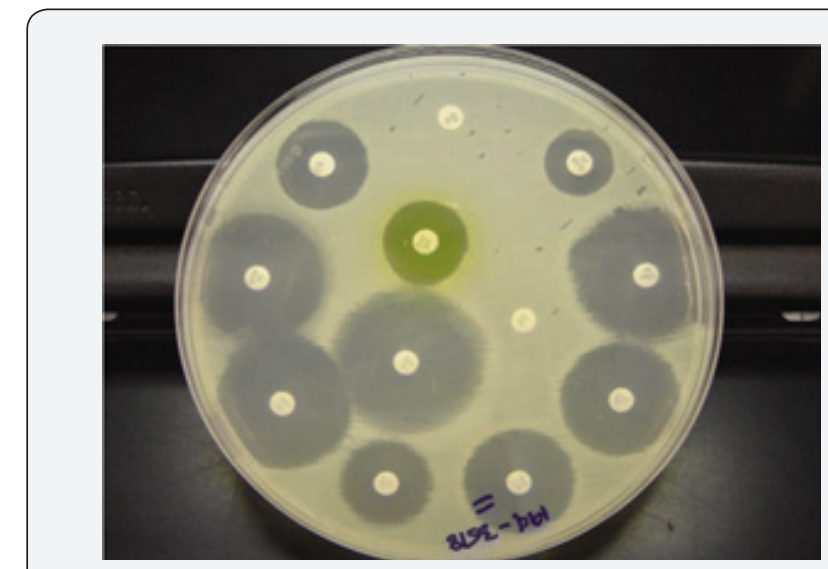

Figure 2: Disk diffusion test with an isolate of Escherichia coli from a urine culture.

The disk diffusion susceptibility method is simple and practical and has been well-standardized. The test is performed by applying a bacterial inoculum of approximately 1-2×108CFU/mL to the surface of a large (150 mm diameter) Mueller-Hinton agar plate. Up to 12 commercially-prepared, fixed concentration, paper antibiotic disks are placed on the inoculated agar surface (Figure 2). Plates are incubated for $16-24 \mathrm{~h}$ at $35^{\circ} \mathrm{C}$ prior to determination of results. The zones of growth inhibition around each of the antibiotic disks are measured to the nearest millimeter. The diameter of the zone is related to the susceptibility of the isolate and to the diffusion rate of the drug through the agar medium. The zone diameters of each drug are interpreted using the criteria published by the Clinical and Laboratory Standards Institute (CLSI, formerly the National Committee for Clinical Laboratory Standards or NCCLS) or those included in the US Food and Drug Administration (FDA)-approved product inserts for the disks. The results of the disk diffusion test are "qualitative," in that a category of susceptibility (ie, susceptible, intermediate, or resistant) is derived from the test rather than Minimum Inhibitory Concentration (MIC). However, some commercially-available zone reader systems claim to calculate an approximate MIC with some organisms and antibiotics by comparing zone sizes with standard curves of that species and drug stored in an algorithm [16].

\section{Molecular drug susceptibility tests}

Historically drug susceptibility testing has been done through culturing bacteria. It has needed specific laboratory facilities and trained personnel. In addition, it is a very lengthy process. There are however now some new tests available one of which is the GeneXpert test. This is much easier to use, but it only provides limited information about drug resistance. 


\section{GeneXpert test}

Since resistance arises from genetic mutations, this approach is to detect the mutations themselves. Many mutations associated with resistance have been identified and molecular tests to detect them have been developed. The advantages of molecular methods of drug susceptibility testing include rapid turnaround times, but the disadvantages include a low sensitivity for some compounds, and a major issue is cost. It is generally perceived that specialist staff are required in order to perform molecular assays. However, some assays such as the GeneXpert are extremely easy to use. They can even be taken out of the laboratory setting and used as a "near" point of care test.

\section{Common Disease of Poultry and their Resistance Against Specific Antimicrobial Agent}

\section{Escherichia. Coli}

Escherichia coli (E.) coli is a Gram-negative, facultative anaerobe bacterium of the Enterobacteriaceae family. Since E. coli is ubiquitous in the gastrointestinal tract of warm-blooded animals. Certain E. coli strains, designated as "avian pathogenic E. coli (APEC) are causative agents of colibacillosis, one of the principal causes of morbidity and mortality in poultry worldwide. It has been extensively used to monitor AMR in food animals (including poultry). In addition, some E. coli strains hosted by poultry are potential source of AMR genes that may transmit to humans [17].

A study from China identified floR, cmlA, cat1, cat2, and cat3 (genes associated with florfenicol and chloramphenicol resistance) among APEC strains [18]. In another study from the same country, the presence of class I integrins on isolates from the same country was strongly correlated with multi-drug resistance (93.3\% MDR strains were positive for class 1 integron, compared with $12.5 \%$ among non-MDR strains) [19]. In a study from Egypt integrons (mostly class 1 ) were detected in $29.3 \%$ isolates and were associated with the presence of genes encoding for resistance to trimethoprim (dfrA1, dfrA5, dfrA7, dfrA12), streptomycin/ spectinomycin (aadA1, aadA2, aadA5, aadA23), and streptothricin (sat2). Other, non-integron-associated resistance genes included tetracycline (tetA and tetB), ampicillin (blaTEM), chloramphenicol (cat1), kanamycin (aphA1), and sulfonamide (sul1 and sul2). The S83L mutation in the gyrA gene (present in $23.2 \%$ isolates) was the most frequently genetic determinant of quinolone resistance, followed by qnrA, qnrB, and qnrS genes. A previous study on 73 APEC strains from the same country (of which $67.0 \%$ were nalidixic resistance, $15.1 \%$ ciprofloxacin resistance), plasmid-mediated quinolone resistance genes qnrA1, qnrB2, qnrS1 were found in $64.0 \%$ isolates, and the fluoroquinolone-modifying acetyltransferase gene (aac(6_)-Ib-cr) in $7.0 \%$ isolates. A study on a large collection (980) of APEC isolates from several countries identified the plasmid-mediated mcr-1 colistin resistance gene in 8 isolates from China (of 31 tested) and 4 from Egypt (of 20 teste Most such strains were multi-resistance to 10 or more antimicrobials.

\section{Salmonella pullorum/gallinarum}

Bacteria of the genus Salmonella are Gram-negative, facultative anaerobic, nonspore forming, usually motile rods belonging to the Enterobacteriaceae family, which are associated with the alimentary tract of animals. Salmonellae reduce nitrates to nitrites, carbon dioxide and hydrogen gases are usually produced from D-glucose, and hydrogen sulfide is typically produced by most salmonellae. Nearly, all salmonellae are aerogenic except for Salmonella serovar Typhi which never produce gas. Tests for indole production (tryptophanase), oxidase, and urease are negative and 16S rRNA sequence analyses indicate that Salmonella belong to the Gammaproteobacteria [20].

Salmonella Pullorum/Gallinarum are biovars within the genus S. enterica subspecies enterica within the family Enterobacteriaceae. They are the etiological agents of pullorum disease (S. Pullorum) and fowl typhoid (S. Gallinarum), two septicemic diseases widely common in much of the world, though they have been eradicated from commercial poultry operations in many developed countries. A study from Korea reported an increase over time in phenotypic resistance among $S$. Gallinarum isolates: whereas in 1995 all isolates were fully susceptible to 12 antimicrobials, except for tetracycline (>83\% resistance), by 2001 , levels of resistance were: ampicillin (87.0\%), gentamicin (56.6\%), kanamycin (30.4\%), enrofloxacin (93.5\%), ciprofloxacin (89.1\%), norfloxacin (47.5\%), and ofloxacin (17.4\%) [21]. Over the same period, the MIC range for enrofloxacin, ciprofloxacin, norfloxacin, ofloxacin also increased considerably, in parallel with an increase in the rate of mutations of the gyrA (from 5.6 to 89.1\%) [21]. A further study from the same country unexpectedly identified $S$. Gallinarum in table eggs from healthy chicken layer flock.

Antimicrobial resistance mechanisms Salmonella by antimicrobial class of Aminoglycosides were first discovered in 1943 when streptomycin was isolated from Streptomyces griseus [22]. Other commonly known compounds in this class of drugs include gentamicin, neomycin, amikacin, and kanamycin [22]. These drugs are effective for treating infections caused by Gram-negative bacilli and are usually used in combination with glycopeptides and $\boldsymbol{\beta}$-lactams to ensure a broad spectrum of action [23]. Aminoglycosides bind to conserved sequences within the $16 \mathrm{~S}$ rRNA of the $30 \mathrm{~S}$ ribosomal subunit which leads to codon misreading and translation inhibition. Most aminoglycosides are bactericidal with the exception of spectinomycin, which is bacteriostatic [24]. Primary mechanisms for nontyphoidal Salmonella to resist aminoglycosides are 1) decreased drug uptake, 2) drug modification, and 3) modification of the ribosomal target of the drug [25].

Two mechanisms of are implicated in the spread of antimicrobial resistance in Salmonella populations: The first was horizontal transfer of genes for antibiotic resistance, and the second was clonal spread of antimicrobial drug resistant Salmonellaisolate [26]. Resistance genes can be horizontally transferred between Salmonella strains or from other bacterial species to the Salmo- 
nella strains. In Salmonella, plasmids, and Class I integrons are primarily responsible for horizontal [27] transmission [28]. Other species can contribute resistance genes not currently found in the Salmonella gene pool through this mechanism. Resistance genes for the various antimicrobial drug classes can be found on several different plasmid types and many of these plasmids carry multiple antimicrobial resistance genes which can be transferred to other Salmonella and other bacterial species. Integrons are elements that contain the genetic determinants of components of a site-specific recombination system that recognizes and captures mobile gene cassettes [29]. Integrons contain the gene for an integrase (i.e., int) and an adjacent recombination site. Although gene cassettes are not necessarily part of the integron once incorporated, they become part of the integron [30] encode resistance to antibiotics or disinfectants [29]. Class I and Class II integrons have been found in Salmonella. Class I integrons are primarily in the Salmonella genomic islands [29] while Class II integrons are embedded in the TN7 transposon family but have not been fully described [31].

\section{Pasteurella multocida}

Pasteurellamultocida is a Gram-negative, non-motile, facultative anaerobic bacterium of the Pasteurellaceae family. It is the causative agent of fowl cholera, a disease that often manifests as acute fatal septicemia in adult birds, although chronic, and asymptomatic infections also occur [32]. A study on 120 isolates from poultry in India showed $100 \%$ resistance against sulfadiazine, a drug most often used in the field to treat fowl cholera in that country. Only resistance against chloramphenicol, ciprofloxacin, norfloxacin, enrofloxacin, gentamicin, and lincomycin, was observed in $<10 \%$ isolates, remaining the only effective therapeutic alternatives. In another study of 56 poultry isolates from Brazil, levels of resistance were highest for sulfonamides (sulfaquinoxaline) $(\sim 77 \%)$; in contrast levels of resistance against $\beta$-lactams (amoxicillin, ceftiofur), aminoglycosides (gentamicin), and macrolides (erythromycin) were $<6 \%$. In a study from the United States of 80 isolates, resistance was less than $7 \%$ against all antimicrobials. In comparison with E. coli and Salmonella isolates, P. multocida isolates from poultry were found to be much more susceptible to the antimicrobials tested [33]. It is not known whether this explains the relatively lower prevalence of AMR in P. multocida compared with other Gram-negative bacteria [34].

Studies on isolates from pigs, cattle, and poultry in Europe have shown that resistance in $P$. multocida is generally mediated by small (4-7 kb size) plasmids. A larger plasmid (pVM111) has also been shown to contain multiple genes conferring resistance against tetracycline, sulfonamides, and streptomycin resistance (tetR-tet $(\mathrm{H})$, sul2, and strA), supporting the hypothesis that the spread of resistance is due to horizontal transfer of plasmids rather than clonal dissemination [35].

\section{Clostridium perfringens}

Clostridium perfringens is a Gram-positive, rod-shaped, anaerobic, spore-forming bacterium commonly found in the intestinal tract of poultry, other animals and the environment. Under certain conditions, the bacterium can multiply, causing necrotic enteritis, and cholangiohepatitis, two E. Coli and C. Perfringen) diseases that are responsible for heavy losses in the broiler and turkey industry worldwide [36]. A total of seven publications have investigated phenotypic resistance in 564C. perfringens isolates from Belgium, Scandinavia, Egypt, Korea, Brazil, and Canada. All studies investigated chicken isolates, except one that also included isolates from turkey species [37].

A number of studies have investigated resistance against antimicrobials commonly used as growth promoters (bacitracin, avilamycin, virginiamycin) in addition to coccidiostats (i.e., salinomycin, monensin) that are also known to have activity against Clostridium spp. in the gut [38]. A study from Taiwan reported MIC50 values of erythromycin and lincomycin for $C$. perfringens isolated from intestinal samples with severe lesions were significantly higher compared with those with mild lesions [39]. However, a study from Korea compared resistance patterns between isolates from healthy and sick flocks and found no difference [40]. Studies on $C$. perfringens isolates from Canadian chickens and turkeys had overall higher levels of resistance against bacitracin and virginiamycin compared with bovine and porcine isolates [37], but not for other antimicrobials tested. Studies in Belgium and Scandinavia have identified tetP $(\mathrm{B})$, tet $(\mathrm{M})$, tetA $(\mathrm{P})$, and tetB $(\mathrm{P})$ genes among tetracycline resistant isolates). Genelnu (A) and lnu (B) genes associated with low-level resistance against lincomycin have identified strain from Belgium [41].

\section{Mycoplasma species}

Mycoplasma spp. is mollicutes bacteria that lack a cell wall around their membrane. M. gallisepticum infection is particularly important as a cause of respiratory disease and decreased meat and egg production in chickens and turkeys worldwide. Other species such as M. synoviae, M. meleagridis, and M. iowae can also cause disease in poultry. Since Mycoplasma spp. are fastidious organisms, routine methods based on isolation and phenotypic testing of resistance are not practicable. Mycoplasma spp. are unaffected by many common antibiotics that target cell wall synthesis. Antimicrobials commonly used to treat Mycoplasma spp. infections include tetracycline, macrolides (tylosin, tilmicosin), and more recently, fluoroquinolones (enrofloxacin, difloxacin), and pleuromutilins (tiamulin) [42].

In vitro studies involving passages in sub-inhibitory concentrations of antimicrobials have shown resistance to macrolides can be quickly acquired among poultry Mycoplasma spp., whereas resistance to enrofloxacin develops more gradually. No resistance to tiamulin or oxytetracycline could be evidenced in M. gallisepticum or M. synoviae after 10 passages, whereas M. iowae resistant mutants were obtained. Mycoplasma spp. mutants that became resistant to tylosin were also resistant to erythromycin, whereas mutants made resistant to erythromycin were not always resistant to tylosin [43]. A study on M. gallisepticum and M. synoviae isolated from chickens and turkeys in Israel collected during 
2005-2006 indicated a reduction in susceptibility against fluoroquinolones (enrofloxacin and difloxacin) compared with archived strains (1997-2003) [44]. Similarly, a study from Jordan compared MICs in isolates collected from 2004 to 2005 vs. strains collected during 2007-2008 confirmed a significant increase in MIC against 8 (erythromycin, tilmicosin, tylosin, ciprofloxacin, enrofloxacin, chlortetracycline, doxycycline) of 13 antimicrobials tested [45]. A study on $20 \mathrm{M}$. gallisepticum isolates from Thailand where $M$. gallisepticum isolates were further characterized into groups $(\mathrm{A}$, $\mathrm{B}, \mathrm{C}, \mathrm{D}, \mathrm{U}$ ) by random amplification of polymorphic DNA reported the lowest MICs for doxycycline, tiamulin, and tylosin among all tested drugs. Some M. gallisepticum isolates low-level resistant to josamycin and were resistant to enrofloxacin and erythromycin [46]. Tiamulin (pleuromutilin) has been found in general to be a useful drug in the treatment and control of Mycoplasma spp. infection. However, administering tiamulin to flocks medicated with ionophore antimicrobials is not recommended, since it may lead to toxicity [47]. Fluoroquinolone resistance in Mycoplasma spp. is of great concern, since enrofloxacin is often the drug of choice to treat infections in poultry. However, a study showed that treatment with enrofloxacin did not succeed in eradicating infection from flocks subjected to experimental infection [48]. A study on 93 strains from several countries indicated that M. gallisepticum strains with substitutions in the quinolone resistance-determining regions (QRDRs) of both gyrA and parC are resistant to enrofloxacin, however in $10 \%$ strains with such substitutions did not show a clear correlation with the MIC. The authors concluded that this may limit the applicability of a gene-based assay to detect fluoroquinolone resistance in this avian pathogen.

\section{Other pathogens}

Bordetellaavium (B. avium) is a Gram-negative, strictly aerobic bacterium, of the family Alcaligenaceae. It is the etiological agent of turkey coryza, a respiratory disease of economic importance to the turkey industry [49]. In addition, the organism can however also colonize a range of wild and domestic birds [50]. In addition, B. avium organism is considered to be zoonotic, since it has been isolated from human patients with respiratory disease [51].

Ornithobacteriumrhinotracheale (ORT) is a Gram-negative, rod-shaped bacterium that causes respiratory disease in turkeys, chickens, and other avian species. It was first identified in turkeys in the 1990s. Establishing the antibiotic sensitivity of this pathogen is difficult because of its complex growth requirements. ORT is known to be often resistant to many antimicrobials, and therefore only isolates from wild birds are likely to display the highest degree of susceptibility. Therefore, antimicrobial susceptibility results in these isolates have often been used to compare with those from poultry isolates [52].

Gallibacteriumanatisbiovarhaemolytica is a Gram-negative bacterium of the Pasteurellaceae family. The organism is known to colonize the upper respiratory tract and lower reproductive tract of chickens, but also been experimentally shown to induce clinical infection [53]. G. anatis has previously been misclassified as M. haemolytica, P. hemolytica, P. anatis, and Actinobacillussalpingitidis, but was recently classified as a new genus (Gallibacterium) [54]. A total of three studies have investigated phenotypic resistance in G. anatis [55]. However, in one of them, these isolates were identified as M. haemolytica [56]. However, in the absence of specific breakpoints published, one study only indicated the mean inhibition zone of isolates, indicating that isolates showed maximum sensitivity to norfloxacin $(32 \mathrm{~mm})$ and minimum $(16 \mathrm{~mm})$ to erythromycin [57].

Avibacteriumparagallinarum (previously $H$. paragallinarum) is a capsulated, rod-shaped, Gram-negative facultative anaerobe bacterium of the Pasteurellaceae family. It is the etiological agent of infectious coryza, an acute disease of the upper respiratory tract of chickens worldwide [58]. A study on isolates from Latin American countries showed the lowest level of resistance against co-trimoxazole (potentiated sulfonamide). However, the authors remind that sulfonamides should be administered with caution in poultry given their low safety margin and the presence of residues in meat and eggs for a relatively longer period [59]. A study of four A. paragallinarum isolates in Tanzania detected genes associated with streptomycin (strA), ampicillin (blaTEM), tetracycline (tetC and tetA), and sulfamethoxazole (sul2) resistance [60]. In a study of 18 isolates from Taiwan about $72 \%$ isolates contained plasmids pYMH5 and pA14 [61].

\section{Problem of antimicrobial resistance in poultry patho- gens in Ethiopia}

Ethiopia has about 56.87 million chickens comprising mainly indigenous chickens, with the majority (95\%) kept in low-input low-out-put village chicken production systems. Chicken provides an important source of income in addition to offering eggs and meat for the poor smallholder households in Ethiopia. However, the $0.5 \mathrm{~kg}$ annual per capita egg consumption in Ethiopia is five times lower than the average $2.3 \mathrm{~kg}$ per capita for other sub-Sahara African countries [62]. The Ethiopian indigenous chickens cannot be produced and fill the national demand for chicken meat and eggs despite the fact that they harbor suitable phenotypic traits for ecological, social and cultural context of Ethiopia. The emergence and spread of such drug resistant strains among food animals including chickens is life threatening and a global public health concern, as they are often non-treatable with currently available antimicrobials [63]. Animal agriculture such as poultry farming and antibiotic usage on the farms are a hot debate topic, because the overuse may be a contributing factor for the entrance of AMR pathogens and AMR genes to the food chain [64]. Antibiotic-resistant Salmonella infections of both human and animal are universal concerns, particularly in developing countries where the risk of infection is high because of unhygienic living conditions, close contact and sharing of houses between animals and humans, and the traditions of consumption of raw or undercooked animal-origin food items [65-68]. There is an increasing concern with this pathogen due to the emergence and spread of antibiotic-resistant and potentially more pathogenic strains. Antimicrobial-resistant 
Salmonella spp. have been isolated from different foods of animal origin around the world, which is attributed to the inappropriate use of antimicrobials as therapeutic or prophylactic agents in human and veterinary medicine, as well as the use of growth promoters in animal production $[69,70]$.

\section{Prevention and control of antimicrobial resistance in poultry farm}

the Facts about Antimicrobials in poultry and Their Impact on Resistance made the following prevention measure should be carried out:

1) Antimicrobial agents should not be used in poultry in the absence of disease,

2) Antimicrobials should be administered to poultry only when prescribed by a veterinarian,

3) Quantitative data on antimicrobial use in poultry should be made available to inform public policy,

4) The ecology of antimicrobial resistance should be considered by regulatory agencies in assessing human health risk associated with antimicrobial use in poultry,

5) Surveillance programs for antimicrobial resistance should be improved and expanded, and

6) The ecology of antimicrobial resistance in poultry should be a research priority [160]. Implementation of these six-prevention measure along with further research into the mechanisms and the ecology of antimicrobial resistant bacteria, especially Salmonella species, may provide a return to the effectiveness of antimicrobials in treating infections caused by pathogenic bacteria.

In order to control the problem: use of right dosage of antimicrobial, use of right antimicrobial for the right pathogen and check whether the resistance of antimicrobial occur in vitro are some of the control measure should be carried out.

\section{Conclusion and Recommendation}

Among Enterobacteriaceae, E. coli displayed consistently higher levels of resistance against most antimicrobials tested compared with S. Pullorum/Gallinarum.

There are important gaps in the knowledge on AMR in important zoonotic pathogens of poultry. Control of bacterial diseases in poultry often relies on the use of prophylactic antimicrobial treatment at different critical points during the rearing period. Given the observed prevalence of AMR it would be expected that in cases where the pathogen is resistant, the use of certain antimicrobials would result in treatment failure. It would be desirable to identify the burden of disease for each pathogen in each country, and if the disease burden justifies it, implement prophylactic vaccination. In most countries including Ethiopia, farming is conducted without veterinary supervision, and a wide range of antimicrobials is normally available to farmers. Prudent use practices should include restricting the access for use of antimicrobials that are considered to be important for human medicine in animal production. Such restrictions are only currently being enforced only in a number of industrialized countries. Measures such as education on good farming practices, limiting the availability of antimicrobials, and building up a knowledge base on the AMR profile of poultry pathogens will encourage responsible AMU, contributing to reduce treatment failure of poultry diseases. Base on the above conclusion the following points are recommended:

a. Application of appropriate legislation to support the responsible and prudent use of antimicrobial agents in veterinary medicine.

b. Provide knowledge and/or training that can provide stakeholders with information on the benefits of prudent antimicrobial use and the risks associated with inappropriate use.

c. Supply appropriate resources that impact negatively on efforts to develop surveillance and monitoring programmers, education strategies, evaluation and licensing of antimicrobials and efforts to combat the distribution and use of illegal and counterfeit products.

d. Identification of a core set of relevant antimicrobials when developing and implementing prospective testing for surveillance systems for determination of AMR in the food chain.

\section{Acknowledgments}

Firstly, I would like to thank my almighty god in sustaining my life. My gratitude also goes to my lovely families for their love, encouragement and unreserved financial support throughout my student life. I would like to thank my lovely partner Dr. Meksud Mohammed for his encouragement and logistic support for me.

\section{References}

1. Saylers AA, Whitt DD (2004) Revenge of the Microbes: How Bacterial Resistance is undermining the Antibiotic Miracle 2005 ASM Washington DC, In: Shivachandra SB, et al. (Eds.), Antibiotic sensitivity patterns among Indian strains of avian Pasteurellamultocida. Trop Anim Health Prod 36: 743-750.

2. WHO (2014) Antimicrobial Resistance? Global Report on Surveillance.

3. Marshall BM, Levy SB (2011) Food animals and antimicrobials: impacts on human health. Clin Microbiol Rev 24(4): 718-733.

4. Van Boeckel TP, Brower C, Gilbert M, Grenfell BT, Levin SA, et al. (2015) Global trends in antimicrobial use in food animals. Proc Natl Acad Sci USA 112(18): 5649-5654.

5. Simoneit C, Burow E, Tenhagen BA, Käsbohrer A (2015) Oral administration of antimicrobials increase antimicrobial resistance in E. coli from chicken-a systematic review. Prev Vet Med 118(1): 1-7.

6. Bortolaia V, Espinosa-Gongora C, Guardabassi L (2016) Human health risks associated with antimicrobial-resistant enterococci and Staphylococcus aureus on poultry meat. Clin Microbiol Infect (2016) 22: 130140.

7. Luna-Galaz GA, Morales-Erasto V, Peñuelas-Rivas CG, Blackall PJ, Soriano-Vargas E (2016) Antimicrobial sensitivity of Avibacterium paragallinarum isolates from four Latin American countries. Avian Dis 60(3): 673-676.

8. Custer B, Steele JA, Wilcox BA, Xu J (2015) Intensified food production and correlated risks to human health in the Greater Mekong Sub region: a systematic review. Environ Health 14: 43. 
9. Food and Agriculture Organization of the United Nations (2017) FAOSTAT: Live Animals Data.

10. Agunos A, Leger D, Carson C (2012) Review of antimicrobial therapy of selected bacterial diseases in broiler chickens in Canada. Can Vet J 53(12): 1289-1300.

11. Page SW, Gautier P (2012) Use of antimicrobial agents in livestock. Rev Sci Tech 31(1): 145-188.

12. World Health Organization (2017) Critically Important Antimicrobials for Human Medicine, $5^{\text {th }}$ Revision.

13. Ericsson JM, Sherris JC (1971) Antibiotic sensitivity testing: report of an international collaborative study. Acta Pathol Microbiol Scand 217: 1-90.

14. Jorgensen JH, Turnidge JD. Murray PR, Baron EJ, Jorgensen JH, et al. (2007) Antibacterial susceptibility tests: dilution and disk diffusion methods, Manual of clinical microbiology. ( $9^{\text {th }}$ edn), Washington, DC American Society for Microbiology pp. 1152-1172.

15. Balows A (1999) Current techniques for antibiotic susceptibility testing.

16. Korgenski EK, Daly JA (1998) Evaluation of the BIOMIC video reader for determining interpretive categories of isolates on the basis of disk diffusion susceptibility results. J Clin Microbiol 36(1): 302-314.

17. Kheiri R, Akhtari L (2016) Antimicrobial resistance and integron gene cassette arrays in commensal Escherichia coli from human and animal sources in IRI. Gut Pathog 8: 40.

18. Li XS, Wang GQ, Du XD, Cui BA, Zhang SM, et al. (2007) Antimicrobial susceptibility and molecular detection of chloramphenicol and florfenicol resistance among Escherichia coli isolates from diseased chickens. J Vet Sci 8(3): 243-247.

19. Dou X, Gong J, Han X, Xu M, Shen H, et al. (2016) Characterization of avian pathogenic Escherichia coli isolated in eastern China. Gene (2016) 576(1-2): 244-248.

20. Popoff MY, Le Minor LE, Brenner DJ, Kreig NR, Staley JT (2005) Genus XXXIII. Salmonella Bergey's Manual of Systemic Bacteriology ( $\left.2^{\text {nd }} e d n\right)$, East Lansing, MI Springer pp. 764-799.

21. Lee YJ, Kim KS, Kwon YK, Tak RB (2003) Biochemical characteristics and antimicrobials susceptibility of Salmonella gallinarum isolated in Korea. J Vet Sci 4(2): 161-166.

22. Gonzales LS, Spencer JP (1998) Aminoglycosides: A practical review. Am Fam Physician 58: 1811-1820.

23. Graham JC, Gould FK (2002) Role of aminoglycosides in the treatment of bacterial endocarditis. J Antimicrob Chemother 49(3): 437-444.

24. Mascaretti OA (2003) Bacteria versus Antimicrobial Agents: An Integrated Approach ASM Washington, USA.

25. Alcaine SD, Warnick LD, Wiedmann M (2007) Antimicrobial resistance in nontyphoidal Salmonella. J Food Prot 70(3): 780-790.

26. Molbak K, Baggesen DL, Aarestrup FM, Ebbesen JM, Engberg J, et al. (2016) Antimicrobial usage and antimicrobial resistance in animal production in southeast Asia: a review. Antibiotics (Basel) 5(4): E37.

27. Guerra B, Soto S, Helmuth R, Mendoza MC (2002) Characterization of a self-transferable plasmid from Salmonella enterica serotype Typhimurium clinical isolates carrying two integrin-borne gene cassettes together with virulence and drug resistance genes Antimicrob. Agents Chemother 46(9): 2977-2981.

28. Duguma R (2009) Understanding the role of indigenous chicken during the long walk to food security Ethiopia. Livestock Res Rural Dev 21: 116.

29. Fluit AC (2005) Towards more virulent and antibiotic-resistant Salmonella? FEMS Immunology. Med Microbiol 43(1): 1-11.
30. Villa L, Carattoli A (2005) Integrons and transposons on the Salmonella entericaserovar Typhimurium virulence plasmid Antimicrob. Agents Chemotherap 49(3): 1194-1197.

31. Carattoli A (2003) Plasmid-mediated antimicrobial resistance in Salmonella enterica. Curr Issues Mol Biol 5: 113-122.

32. Anon. Fowl cholera (2015) In: Office International des Epizooties, editor., editor. OIE Terrestrial Manual 2015. Paris: Office International des Epizooties p. 1-11.

33. Huang TM, Lin TL, Wu CC (2009) Antimicrobial susceptibility and resistance of chicken Escherichia coli, Salmonella spp., and Pasteurellamultocida isolates. Avian Dis 53(1): 89-93.

34. Kehrenberg C, Tham NT, Schwarz S (2003) New plasmid-borne antibiotic resistance gene cluster in Pasteurellamultocida. Antimicrob Agents Chemother 47: 2978-2980.

35. San Millan A, Escudero JA, Gutierrez B, Hidalgo L, Garcia N, et al. (2009) Multiresistance in Pasteurellamultocida is mediated by coexistence of small plasmids. Antimicrob Agents Chemother 53(8): 3399-3404.

36. Kaldhusdal M, Benestad SL, Lovland A (2016) Epidemiologic aspects of necrotic enteritis in broiler chickens-disease occurrence and production performance. Avian Pathol 45(3): 271-274.

37. Slavic D, Boerlin P, Fabri M, Klotins KC, Zoethout JK, et al. (2011) Antimicrobial susceptibility of Clostridium perfringens isolates of bovine, chicken, porcine, and turkey origin from Ontario. Can J Vet Res 75(2): 89-97.

38. Anon (2015) The risk of development of antimicrobial resistance with the use of coccidiostats in poultry diets. VKM Report. Norwegian Scientific Committee for Food Safety.

39. Fan YC, Wang CL, Wang C, Chen TC, Chou CH, et al. (2016) Incidence and Antimicrobial susceptibility to Clostridium perfringens in premarket broilers in Taiwan. Avian Dis 60: 444-449.

40. Park JY, Kim S, Young Oh J, Hye Ryoung K, Jang I, et al. (2015) Characterization of Clostridium perfringens isolates obtained from 2010 to 2012 from chickens with necrotic enteritis in Korea. Poultry Sci 94(6): $1158-1164$.

41. Martel A, Devriese LA, Cauwerts K, De Gussem K, Decostere A, et al. (2004) Susceptibility of Clostridium perfringens strains from broiler chickens to antibiotics and anticoccidials. Avian Pathol 33(1): 3-7.

42. Bradbury JM, Morrow C (2008) Chapter 20-Avian mycoplasmas. (6 $6^{\text {th }}$ edn), In: Pattison M, McMullin P, Bradbury JM (Eds.), Poultry Diseases. Edinburgh/New York, USA, pp. 220-233.

43. Gautier-Bouchardon AV, Reinhardt AK, Kobisch M, Kempf I (2002) In vitro development of resistance to enrofloxacin, erythromycin, tylosin, tiamulin and oxytetracycline in Mycoplasma gallisepticum, Mycoplasma iowae and Mycoplasma synoviae. Vet Microbiol 88: 47-58.

44. Gerchman I, Lysnyansky I, Perk S, Levisohn S (2008) In vitro susceptibilities to fluoroquinolones in current and archived Mycoplasma gallisepticum and Mycoplasma synoviae isolates from meat-type turkeys. Vet Microbiol 131: 266-276.

45. Gharaibeh S, Al-Rashdan M (2011) Change in antimicrobial susceptibility of Mycoplasma gallisepticum field isolates. Vet Microbiol 150(3-4): 379-383.

46. Pakpinyo S, Sasipreeyajan J (2007) Molecular characterization and determination of antimicrobial resistance of Mycoplasma gallisepticum isolated from chickens. Vet Microbiol 125(1-2): 59-65.

47. Horrox NE (1980) Monensin-tiamulin interaction risk to poultry. Vet Rec 106(12): 278.

48. Reinhardt AK, Gautier-Bouchardon AV, Gicquel-Bruneau M, Kobisch M Kempf I (2005) Persistence of Mycoplasma gallisepticum in chickens after treatment with enrofloxacin without development of resistance. Vet Microbiol 106(1-2): 129-137. 
49. Akeila MA, Saif YM (1988) Protection of turkey poultry from Bordetella avium infection and disease by pili and bacterins. Avian Dis 32(4) 641-649.

50. Ping-Ping Y, Xue Z, Jing-Jing L, Yuan-Li H, Guan-Hua L, et al. (2014) Colonization pattern of Bordetellaavium in experimental infection of chicken. Pak Vet J 34: 193-196.

51. Harrington AT, Castellanos JA, Ziedalski TM, Clarridge JE, Cookson BT (2009) Isolation of Bordetellaavium and novel Bordetella strain from patients with respiratory disease. Emerg Infect Dis 15(1): 72-74.

52. Devriese LA, Hommez J, Vandamme P, Kersters K, Haesebrouck F (1995) In vitro antibiotic sensitivity of Ornithobacteriumrhinotracheale strains from poultry and wild birds. Vet Rec 137: 435-436.

53. Bojesen AM, Nielsen OL, Christensen JP, Bisgaard M (2004) In vivo studies of Gallibacteriumanatis infection in chickens. Avian Pathol 33: 145-152.

54. Christensen H, Bisgaard M, Bojesen AM, Mutters R, Olsen JE (2003) Genetic relationships among avian isolates classified as Pasteurellahaemolytica, 'Actinobacillussalpingitidis' or Pasteurellaanatis with proposal of Gallibacteriumanatis gen Nov comb Nov and description of additional genomospecies within Gallibacterium gen. nov Int J Syst Evol Microbiol 53: 275-287.

55. Jones KH, Thornton JK, Zhang Y, Mauel MJ (2013) A 5-year retrospective report of Gallibacteriumanatis and Pasteurellamultocida isolates from chickens in Mississippi. Poult Sci 92(12): 3166-3171.

56. Malik YS, Chander Y, Gupta SC, Goya SM (2005) A retrospective study on antimicrobial resistance in Mannheimia (Pasteurella) haemolytica, Escherichia coli, Salmonella species, and Bordetellaavium from chickens in Minnesota. J Appl Poult Res 14: 506-511.

57. Akbar A, Naila S, Muhammad Athar A, Abdul G, Saba R, et al. (2015) Role of Mannheimia (Pasteurella) haemolytica in severe respiratory tract Infection in commercial poultry in Pakistan. Pak Vet J 35: 279-282.

58. Blackall PJ, Reid GG (1982) Further characterization of Haemophilus paragallinarum and Haemophilus avium. Vet Microbiol 7(4): 359-367.

59. Landoni MF, Albarellos G (2015) The use of antimicrobial agents in broiler chickens. Vet J 205(1): 21-27.
60. Byarugaba DK, Minga UM, Gwakisa PS, Katunguka-Rwakishaya E, Bisgaard M, et al. (2011) Demonstration of antibiotic resistance genes strA, blaTEM, tetA, tetC and sul2 in Avibacterium paragallinarum. Afr J Microbiol Res 5: 3624-3627.

61. Hsu YM, Shieh HK, Chen WH, Sun TY, Shiang JH (2007) Antimicrobial susceptibility, plasmid profiles and haemocin activities of Avibacteriumparagallinarum strains. Vet Microbiol 124(3-4): 209-218.

62. Boere a, Vernooij a, duns H, Legesse M, Kidane D (2015) Business opportunities report poultry \#3 in the series written for the Ethiopian Netherlands business event. Rijswijk, the Netherlands, p. 5-6.

63. Parveen S, Taabodi M, Schwarz JG. Oscar TP, Harter-Dennis J, et al (2007) Prevalence and AMR of Salmonella recovered from processed poultry. J Food Prot 70(11): 2466-2472.

64. Davis MF, Price LB, Liu CMH, Silbergeld EK (2011) An ecological perspective on US industrial poultry production: the role of anthropogenic ecosystems on the emergence of drug-resistant bacteria from agricultural environments. Curr Opin Microbiol 14(3): 244-250.

65. Charles C, Thomas BJ, Drake C, Kacich G (1999) Clinical and financial benefits of rapid bacterial identification and antimicrobial susceptibility testing). Journal of Clinical Microbiology 37(5): 1415-1418.

66. Blackall PJ (1988) Antimicrobial drug resistance and the occurrence of plasmids in Haemophilusparagallinarum. Avian Dis 32(4): 742-747.

67. Clinical and Laboratory Standards Institute, Methods for dilution antimicrobial susceptibility testing for bacteria that grew aerobically. Approved Standard M7-A10, 2009Wayne, PA Clinical and Laboratory Standards Institute

68. Clinical and Laboratory Standards Institute, Performance standards for antimicrobial susceptibility testing. Nineteenth informational supplement M100-S19, 2009Wayne, PA Clinical and Laboratory Standards Institute

69. Guerra B, Soto SM, Arguelles JM, Mendoza MC (2001) Multidrug resistance is mediated by large plasmids carrying a class 1 integron in the emergent Salmonella enterica serotype Antimicrob. Agents Chemother 45(4): 1305-1308.

70. Van Empel PC, Hafez HM (1999) Ornithobacteriumrhinotracheale: a review. Avian Pathol 28(3): 217-227.

\section{Your next submission with Juniper Publishers will reach you the below assets}

- Quality Editorial service

- Swift Peer Review

- Reprints availability

- E-prints Service

- Manuscript Podcast for convenient understanding

- Global attainment for your research

- Manuscript accessibility in different formats

( Pdf, E-pub, Full Text, Audio)

- Unceasing customer service

Track the below URL for one-step submission https://juniperpublishers.com/online-submission.php 